\title{
TITLE:
}

\section{$<$ Note> A Self-medicating Attempt to Remove the Sand Flea from a Toe by a Young Chimpanzee}

\section{$\operatorname{AUTHOR}(S)$ :}

Nishida, Toshisada

\section{CITATION:}

Nishida, Toshisada. <Note> A Self-medicating Attempt to Remove the Sand Flea from a Toe by a Young Chimpanzee. Pan Africa News 2002, $9(1): 5-6$

ISSUE DATE:

2002-06

URL:

http://hdl.handle.net/2433/143406

RIGHT:

Copyright (C) Pan Africa News. 


\section{$<$ NOTE $>$}

A Self-medicating Attempt to Remove the Sand Flea from a Toe by a Young Chimpanzee

\section{Toshisada Nishida \\ Kyoto University}

On September 25, 2001, an 8-year-old female chimpanzee of M group, I vana, was observed to break a small twig from a shrub, hold its leafy part, and push the sharp edge under the nail of the little toe of her left foot with her right hand (Figure 1). When she failed to insert the probe under the nail, she kept it between her lips, held her left foot with her left hand, and tried to remove something from under the nail with the fingers of her right hand. After she tried to insert the probe several times, she finally threw the probe away after 5 minutes and put her small toe into her mouth, apparently trying to suck something out (Figure 2).

She showed this tool-using behavior after 5 minutes of careful visual inspection of her toe while pushing and scratching it with her right hand, accompanied by the apparent effort to suck something out with her mouth. Although her attention was concentrated on the little toe, at one point she inspected every toe of her left foot. Such visual and manual inspection strongly suggested that she was trying to remove a sand flea (or fleas) from under the nail because such behavior is performed by human beings in the same circumstance. Humans use a safety pin when removing a sand flea. It appears that some chimpanzees of the $M$ group picked up sand fleas when they passed the research camp, which the children of the village occasionally visited. However, I had never observed other chimpanzees applying a probe to their toes, although they inspect and apply fingers to parasitized toes.

An adult male chimpanzee of Mahale regularly pushed a probe into his nostril in order to open up the blocked nasal passage (1). In addition, an adult female who lost her newborn

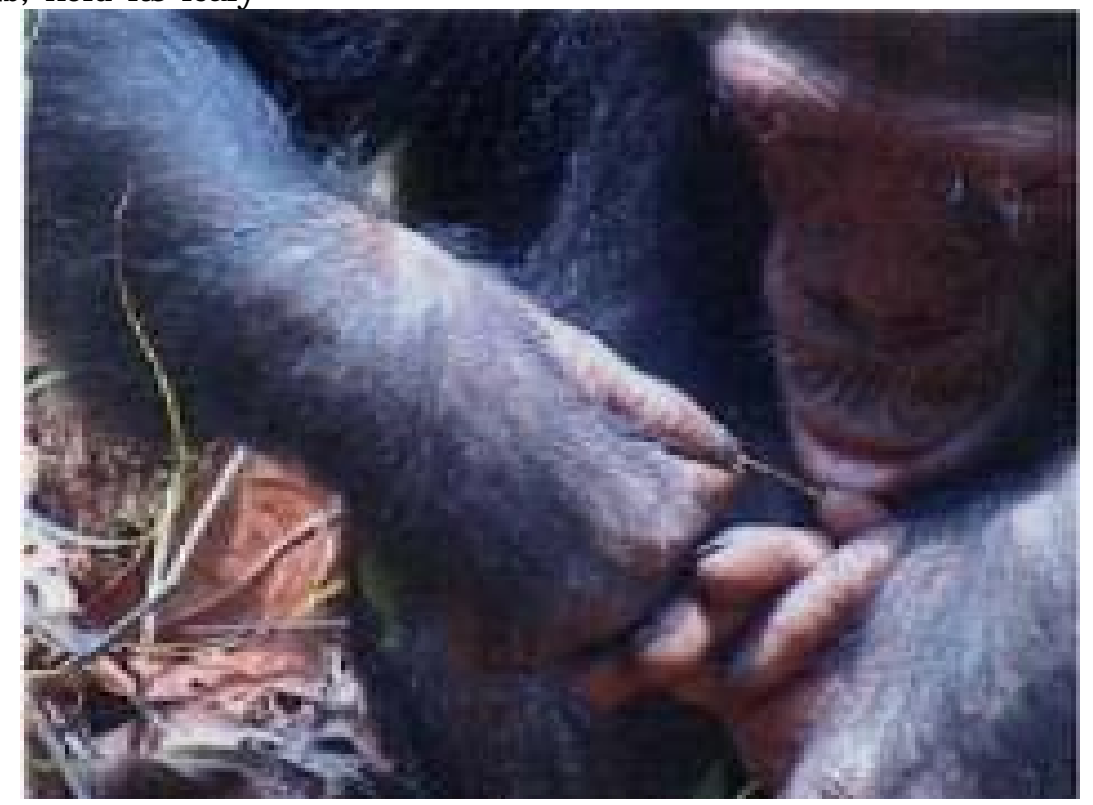

Figure 1. I vana tried to insert a probe under the nail of the little toe.

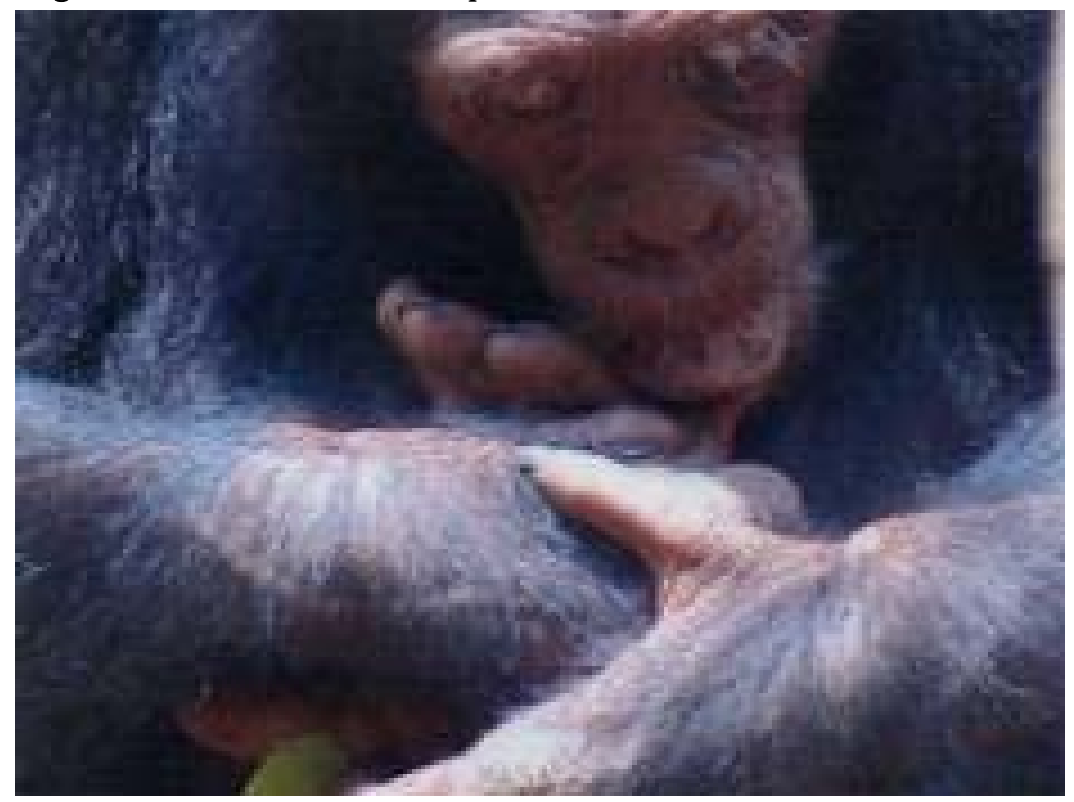

Figure 2. She sucked the little toe. 
was observed to suckle her own nipple, probably to decrease the pain caused by the strained breast (2).

Accordingly, this is the third case of an idiosyncratic pattern of self-medication observed among the chimpanzees of $M$ group. However, I vana failed to remove the sand flea because the branch was too soft and the cutting edge was not sharp enough.

The study was financed by the Monbusho Scientific Research Fund (Basic Research A1, \# 12375003 to TN).

\section{References}

(1) Nishida T, Nakamura M 1993. Chimpanzee tool use to clear a blocked nasal passage. Folia Primatol. 61: 218-220.

(2) Matsumoto-Oda A 1997. Self-suckling behavior by a wild chimpanzee. Folia Primatol. 68: 342-343. 